\title{
Enhanced Performance of Induction Cookers by the Use of Polymer Composites
}

\author{
Yoon Jae Nam¹, Dong Ki Lee' ${ }^{2}$ Jonghan Kwon ${ }^{1}$, K. H. Shin ${ }^{3}$, and S. H. Lim ${ }^{1 *}$ \\ ${ }^{1}$ Department of Materials Science and Engineering, Korea University, Seoul 136-713, Korea \\ ${ }^{2}$ Department of Materials Science and Engineering, KAIST, Daejeon 305-701, Korea \\ ${ }^{3}$ Department of Multimedia Engineering, Kyungsung University, Busan 608-736, Korea
}

(Received 28 July 2010, Received in final form 9 September 2010, Accepted 9 September 2010)

\begin{abstract}
The use of a cooling fan in an induction cooker raises a reliability issue due to the attraction of dust causing a malfunction of the cooling fan and also increases the noise level and power consumption of the device. The purpose of this study is to attempt to solve these problems by molding the $\mathrm{Cu}$ coil of an induction cooker with polymer composites that have a low electrical conductivity but a high thermal conductivity. Among the several polymer composites tested in this study, an aluminum nitride-based composite showed the best performance. The results show that the new induction cooker with the molded composite can operate for an extended period of time without the use of a cooling fan. A further advantage of this new type of induction cooker is that the temperature of the substance in the cooking pot increases more rapidly, indicating an increased efficiency of the induction cooker.
\end{abstract}

Keywords : induction cooker, polymer composites, electrical properties, thermal properties

\section{Introduction}

An induction cooker is a new type of cooking appliance that has a fundamentally different heating mechanism [1], as compared to conventional cooking appliances based on gas or direct Joule (electric) heating. Faraday's law is used for the basic heating mechanism of induction cookers. A magnetic field (known as an Ampere field) is generated by applying a current through a $\mathrm{Cu}$ coil. In most cases, this field is amplified by placing a magnetic material (usually $\mathrm{Mn}-\mathrm{Zn}$ ferrite due to a high operation frequency of several tens of $\mathrm{kHz}$ ) underneath the coil. Eddy currents are then induced in a metallic (and also usually magnetic) cooking pot that is located above the $\mathrm{Cu}$ coil, causing it to heat up through inductive heating. It is clear from this basic operational principle that the $\mathrm{Cu}$ coil plays an important role in induction cookers. The $\mathrm{Cu}$ coil is heated up during the operation, as currents flow through the coil $(\mathrm{Cu}$ loss). The coil can also be heated up due to the heat flow from the cooking pot which can reach as high as $\sim 420^{\circ} \mathrm{C}$ during the operation [2]. For the efficient and reliable operation of the induction cooker, it is important

*Corresponding author: Tel: +82-2-3290-3285

Fax: +82-2-928-3584, e-mail: sangholim@korea.ac.kr to maintain the temperature of the $\mathrm{Cu}$ coil as low as possible [3]. Otherwise, the resistance of the $\mathrm{Cu}$ coil increases, which will then further increase the temperature of the $\mathrm{Cu}$ coil. This positive feedback will eventually result in the malfunction of the cooker. Currently a cooling fan is used to reduce the temperature of the $\mathrm{Cu}$ coil. However, the use of a cooling fan raises a reliability issue, due to the attraction of dust causing a malfunction of the cooling fan. The cooling fan also increases the noise level and the power consumption of the cooker. We propose to solve this problem by molding the $\mathrm{Cu}$ coil with polymer composites. Obviously, the composite should have a high thermal conductivity so that the heat generated in the $\mathrm{Cu}$ coil can be dissipated efficiently. Furthermore, considering that the composite itself is exposed to the ac magnetic field, the polymer composite should also have a high electrical resistivity to minimize the Joule heating of the composite.

\section{Experimental}

Several polymer composites using aluminum nitride (AIN) [4] and boron nitride (BN) [5] powders (or fillers) were fabricated and their performance was tested. Some important physical properties, including the purity and the 
Table 1. Some important physical properties of $\mathrm{BN}$ and $\mathrm{AlN}$ powders that are used for the filler material in the polymer composites.

\begin{tabular}{|c|c|c|c|c|c|}
\hline & & \multicolumn{2}{|c|}{ Boron Nitride } & \multicolumn{2}{|c|}{ Aluminum Nitride } \\
\hline \multicolumn{2}{|c|}{ Powder ID } & $\mathrm{A}$ & $\mathrm{B}$ & $\mathrm{C}$ & $\mathrm{D}$ \\
\hline \multicolumn{2}{|c|}{ Purity (\%) } & 96.5 & 94 & 98 & 95 \\
\hline \multicolumn{2}{|c|}{ Oxygen Content (\%) } & $1.5 \sim 2.0$ & 5.5 & 1.5 & 4.5 \\
\hline Particle & D50 & - & $4 \sim 6$ & $3 \sim 6$ & 12 \\
\hline Diameter $(\mu \mathrm{m})$ & D90 & $10 \sim 14$ & - & 40 & 49.6 \\
\hline \multicolumn{2}{|c|}{ Surface Area $\left(\mathrm{m}^{2} / \mathrm{g}\right)$} & $10 \sim 20$ & $8 \sim 20$ & $2.3 \sim 3.5$ & - \\
\hline \multicolumn{2}{|c|}{ Density $\left(\mathrm{g} / \mathrm{cm}^{3}\right)$} & 2.27 & 2.27 & 3.26 & 3.26 \\
\hline
\end{tabular}

size, are summarized in Table 1. The detailed results of the polymer composites will be published elsewhere. The results showed that the composite based on an AIN powder with a purity of $98 \%$ (Powder C in Table 1) showed the best performance in terms of the temperature increase at the $\mathrm{Cu}$ coil and the power efficiency. Therefore, the present study focused on the AlN-based composite. An epoxy resin (bisphenol A series, NI 660) and a curing agent (MeTHPA, methyltetrahydrophthalic an-hydride, C9H10O3) were used as the matrix for the composite. The epoxy and the curing agent were mixed in a volume ratio of 100:80 and the mixture was stirred for $15 \mathrm{~min}$ using a magnetic stirrer. This mixture, which was heated to $70^{\circ} \mathrm{C}$ in order to reduce its viscosity, was then mixed with the AlN filler in a volume ratio of 100:65 [6]. The AlN powder was surface-treated with silanes before mixing to enhance the bonding between the powder and the polymer matrix [7]. The mixing process took place for the extended time of 3 $\mathrm{hr}$ to ensure the homogeneity of the composite. The next step was to mold the $\mathrm{Cu}$ coil plus an $\mathrm{Al}$ heat sink with the composite. This molding process was carried out at $70^{\circ} \mathrm{C}$. It was important to maintain temperature uniformity in all the related components in order to avoid thermal shock. Then, the whole structure was heated to $112^{\circ} \mathrm{C}$ for $12 \mathrm{hr}$ for curing and then further heated to $140^{\circ} \mathrm{C}$ for $3 \mathrm{hr}$ for hardening, followed by a very slow cooling to room temperature at a rate of $1^{\circ} \mathrm{C} / \mathrm{min}$. A schematic and also a photograph of the molded structure are shown in Figs. 1(a) and (b), respectively. In the schematic diagram (Fig. 1(a)), the molded part is indicated by a gray color. It can be seen from the figure that the $\mathrm{Cu}$ coil and some portion of the heat sink were bonded with the AlN-based composite. Scanning electron microscopy and optical microscopy were used to examine the microstructure of the molded composite. Particular attention was paid to the interface between the $\mathrm{Cu}$ coil and the composite, since the heat dissipation is critically affected by the integrity of the interface.
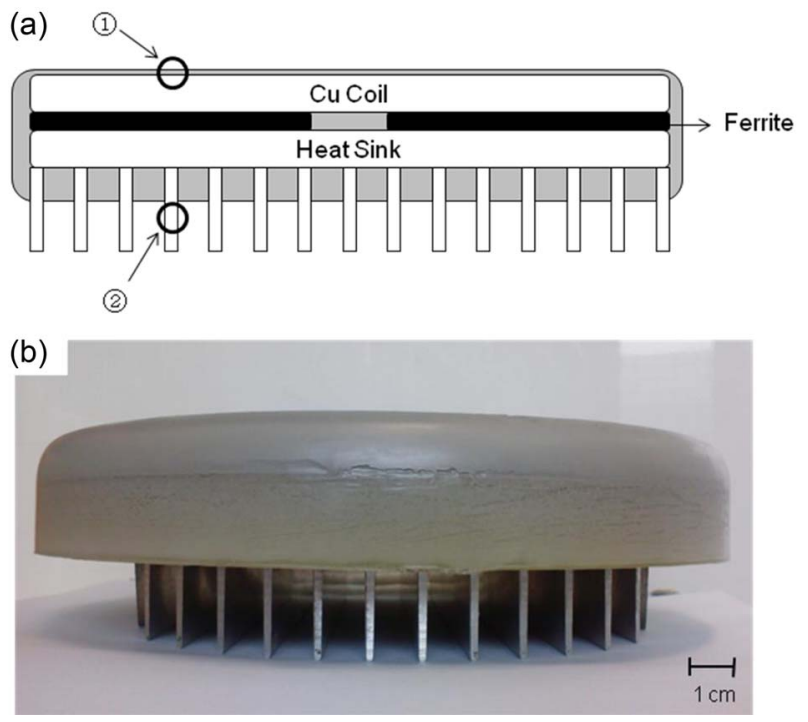

Fig. 1. (a) A schematic diagram of the molded composite that combines the $\mathrm{Cu}$ coil with the $\mathrm{Al}$ heat sink. The locations 1 and 2 are the points of the temperature measurement. (b) A photograph showing the molded composite fabricated in this study.

The molded structure was installed into a commercial induction cooker (model \# BKP-22, Dipo Electronics, Korea [8]) and its performance was characterized by measuring the temperature of both the $\mathrm{Cu}$ coil and the heat sink with thermocouples. The specific locations for the temperature measurement are shown in Fig. 1(a). The experimental procedure for the temperature measurement used in this study was as follows. A cooking pot containing water or soybean oil was heated at maximum power (approximately $2.4 \mathrm{~kW}$ ) and this maximum power was maintained throughout the experiment so that the water or the oil was boiled (and subsequently evaporated) during the temperature measurements. The soybean oil was produced by a local company (CJ Cheiljedang Corp., Korea [9]) with the important properties of a flash point of $262^{\circ} \mathrm{C}$ with a density of $0.924 \mathrm{~g} / \mathrm{cc}$. The conditions of the experiment are significantly harsher than the usual operational conditions of an induction cooker where the power is suitably regulated to maintain a constant temperature. Considering that the water or the oil evaporated during the measurement, a large amount of water $(4 \mathrm{~L})$ or oil (3.6 L) was initially used in order to make for a long temperature measurement time.

\section{Results and Discussion}

Fig. 2(a) shows a scanning electron microscopy image of the epoxy/AIN composite. It can be seen from the 

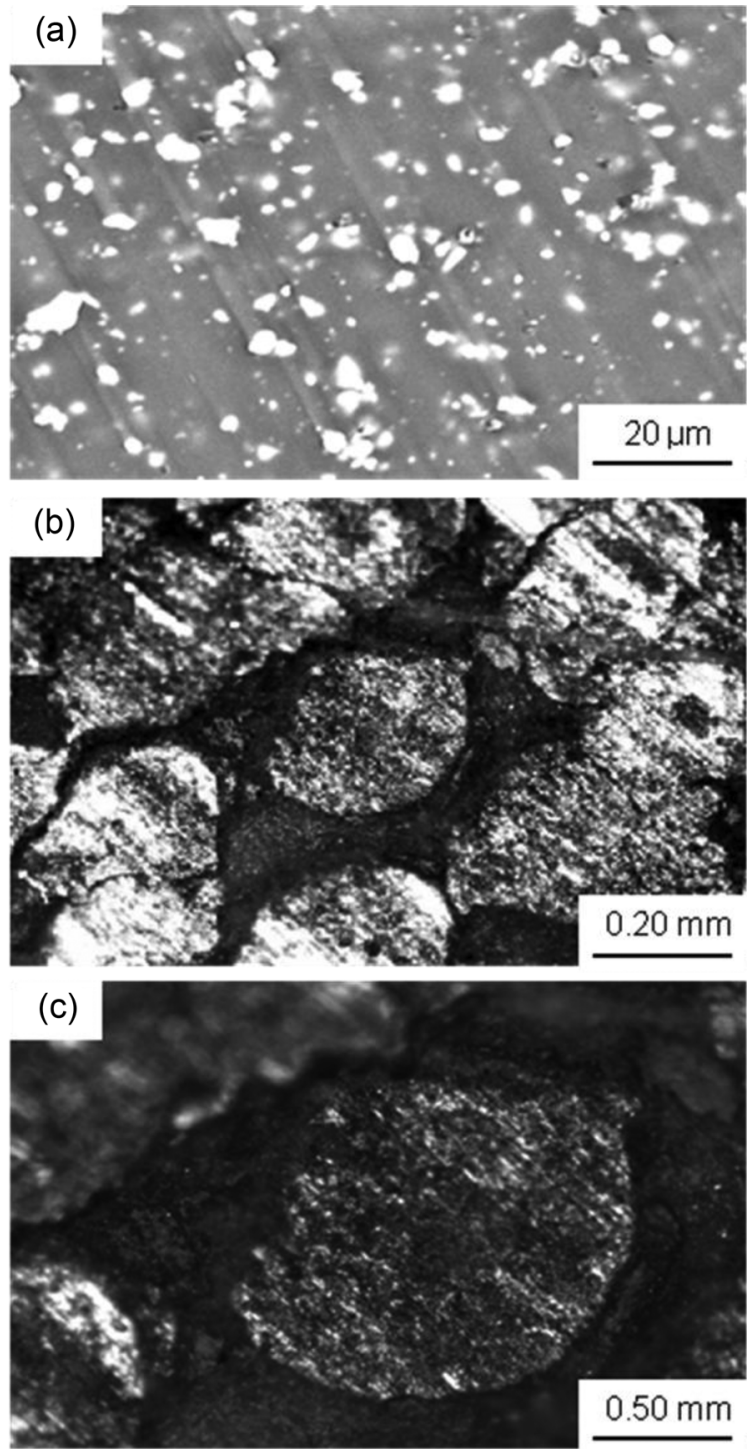

Fig. 2. (a) A scanning electron microscopy image of the polymer composite (epoxy+AIN). The white spots indicate the AlN powders. (b) and (c) Optical microscopy images showing the $\mathrm{Cu}$ wires covered by the polymer composite.

figure that the AlN powder (indicated by white spots) is well-dispersed in the epoxy matrix. Figs. 2(b) and (c) show optical microscopy images revealing the microstructure of the molded composite, in particular the $\mathrm{Cu}$ wire/composite interface, which plays an important role in the transfer of the heat generated by the $\mathrm{Cu}$ wire. Since the frequency of the alternating current through the $\mathrm{Cu}$ coil is in the range of 20 to $60 \mathrm{kHz}$, the diameter of the wire should be comparable to the skin depth $(0.270 \sim 0.467$ $\mathrm{mm}$ ) [10]. Therefore, a bundle of small diameter $\mathrm{Cu}$ wires, instead of a single thick wire, are used in an induction cooker. This feature can be clearly seen in the crosssectional image shown in Fig. 2(b). These optical images

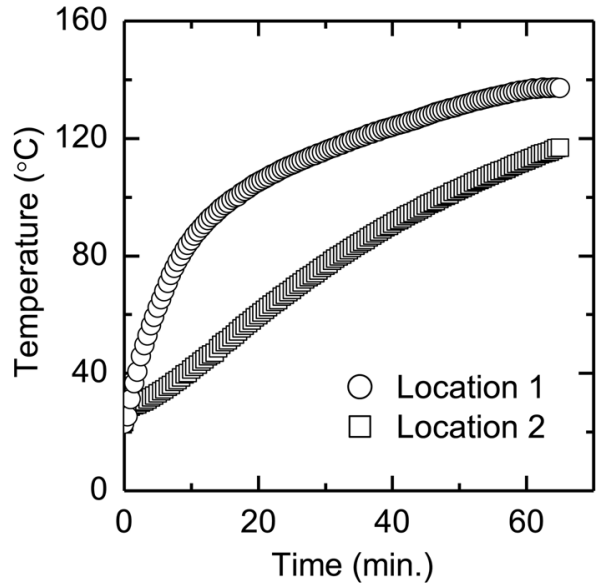

Fig. 3. The change in temperature as a function of the measurement time at two different locations, 1 (near the $\mathrm{Cu}$ coil), and 2 (at the heat sink), as indicated in Fig. 1(a). Water is used as the substance in the cooking pot.

show that the epoxy/AlN composite penetrated well into the $\mathrm{Cu}$ wire. This feature can be seen more clearly in the magnified image in Fig. 2(c), where the composite completely covers the $\mathrm{Cu}$ wire.

In an effort to monitor the heat transfer from the $\mathrm{Cu}$ wire to the heat sink through the epoxy/AIN composite, the temperature was measured at two different locations as indicated in Fig. 1(a). Location 1 is very close to the $\mathrm{Cu}$ wire, at a distance of only $1 \mathrm{~mm}$, while location 2 is further away from the $\mathrm{Cu}$ wire $(40 \mathrm{~mm})$. The temperature results are shown in Fig. 3 as a function of time. The experiment was performed using water as the substance in the cooking pot. The temperature at location 1 (near the $\mathrm{Cu}$ coil) increases quickly for the first $10 \mathrm{~min}$, followed by a slower increase thereafter. The temperature at location 2 , however, has a nearly linear increase over the entire time range measured in this study. The difference of the temperature is at a maximum $\left(47^{\circ} \mathrm{C}\right)$ at $13 \mathrm{~min}$, but this difference decreases continuously with the further increase of time, finally reaching $20^{\circ} \mathrm{C}$ at the longest measurement time of $65 \mathrm{~min}$. This decrease of the temperature difference indicates an increased heat transfer from the source ( $\mathrm{Cu}$ coil) to the heat sink, demonstrating that the heat transfer through the epoxy/AlN occurs efficiently. Of course, in an ideal heat transfer, the difference between the two temperatures would be zero.

The performance of the molded composite can be tested more critically by comparing the temperature increase with that obtained from a conventional induction cooker. The results of the temperature for the two different $\mathrm{Cu}$ coils, measured at location 1 as a function of time, are shown in Figs. 4(a) and (b) where the substances in the 


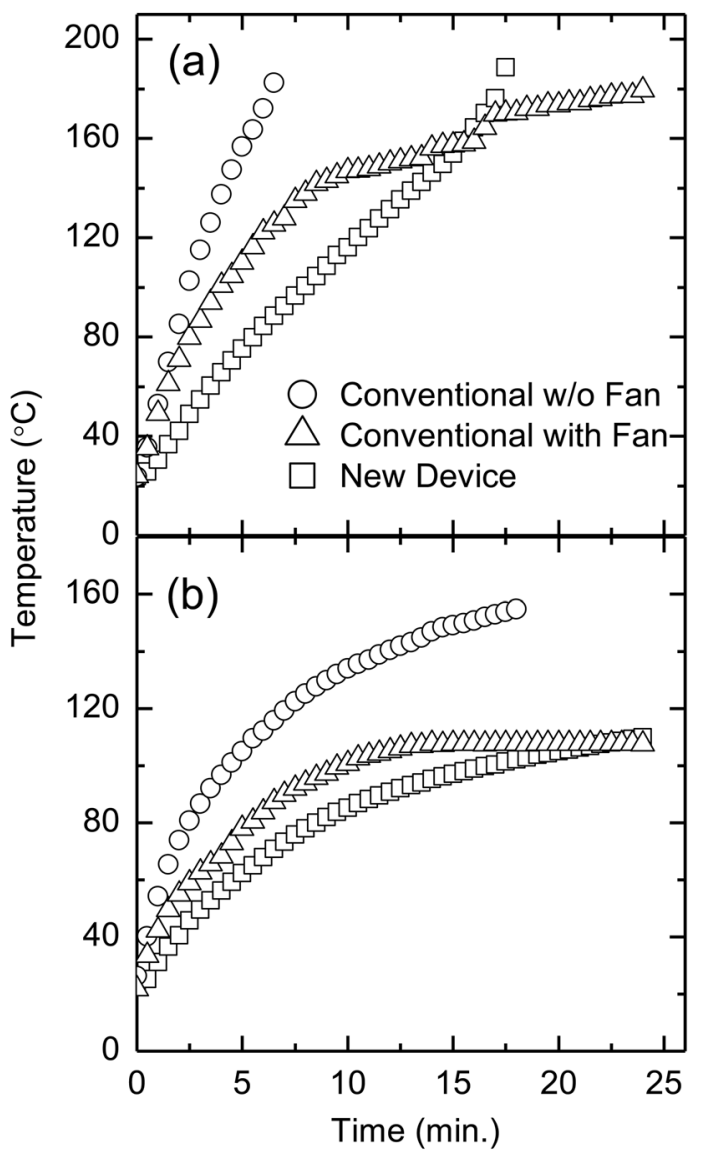

Fig. 4. The change in temperature as a function of measurement time at location 1 (near the $\mathrm{Cu}$ coil). The substances in the cooking pot are (a) oil and (b) water. In both figures, three sets of results are shown: two sets from the conventional induction cooker, one without a cooling fan (circles) and one with a cooling fan installed (triangles), and the third from the new induction cooker with the molded composite developed in this study (squares).

cooking pot are oil and water, respectively. In both figures, three sets of results are shown: two sets from the conventional induction cookers, one without a cooling fan and one with a cooling fan, and the third from the new induction cooker with the molded composite developed in this study. It is important to note that no cooling fan is installed in the new device. In both cases (oil and water), the rate of the temperature increase is substantially steeper in the conventional cookers than in the new one at the early stage (below several minutes) of measurement. A very steep temperature increase is particularly noted for the conventional cooker without a cooling fan. These results clearly demonstrate the improved performance of the new induction cooker with the molded composite. This is of particular note, considering that the new induc-

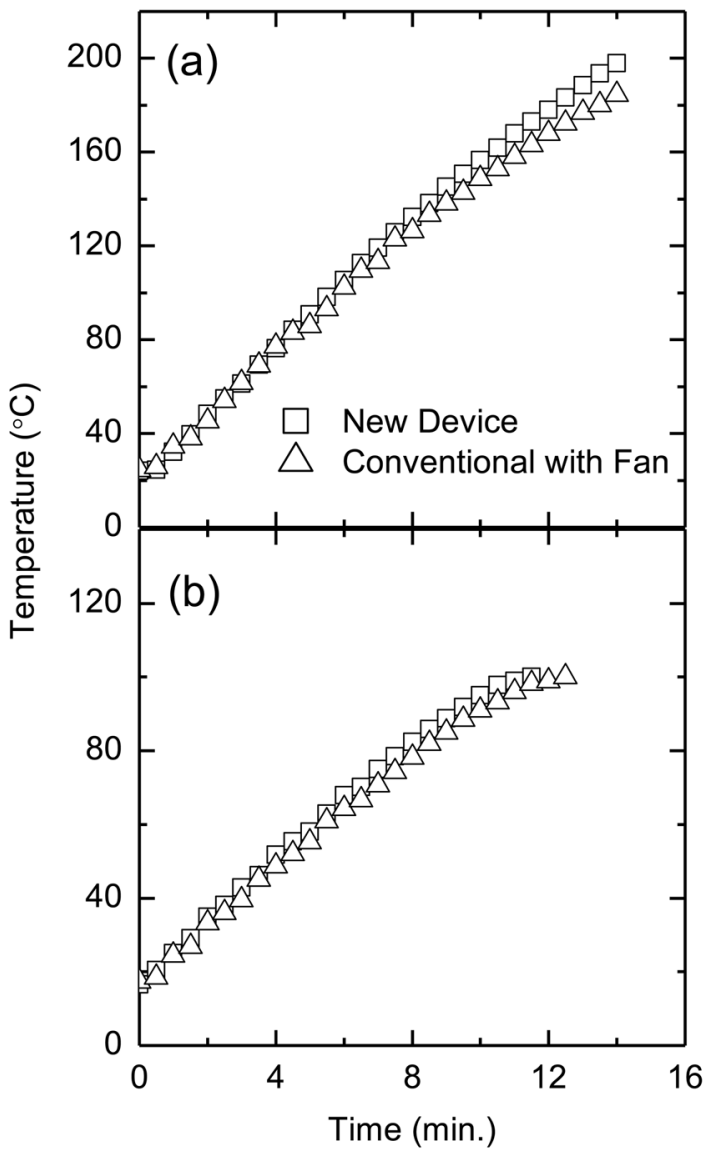

Fig. 5. The change in the temperature of (a) oil and (b) water in the cooking pot as a function of the measurement time. In each case, two sets of results are shown: one from the conventional induction cooker installed with a cooling fan (triangles) and the other from the new induction cooker with the molded composite developed in this study (squares).

tion cooker did not have a cooling fan and the cookers were operated at a full power during the entire measurement time. Later in the experiment, however, a crossover occurs in both the cases of oil and water, where the temperature of the $\mathrm{Cu}$ coil is lower in the conventional cooker than in the new one. This crossover occurs because, in the conventional cooker, the slope of the temperature increase is significantly reduced at an intermediate measurement time ( $\sim 8 \mathrm{~min}$ for oil and $\sim 10 \mathrm{~min}$ for water). A possible reason for this crossover is the absorption of heat from the overheated cooking pot by the composite. This problem could be solved by placing an insulation sheet between the cooking pot and the molded composite [11]. While this result appears to justify the usefulness of the cooling fan, the new induction cooker without a cooling fan should have no problem in an ordinary cooking application where the power is regulated at a level well 
below the full power.

So far, the role of the molded structure has been discussed in reference to the reduction of the temperature of the $\mathrm{Cu}$ coil. It will be interesting to examine how the molded structure affects the temperature of the oil or the water in the cooking pot. The cooling fan cools down not only the $\mathrm{Cu}$ coil and the electronic circuit (a positive effect) but also other parts including the cooking pot (usually indirectly through the ceramic plate holding the cooking pot) (an adverse effect). It is therefore expected that the temperature of the oil or the water will be lower in the presence of a cooling fan. Indeed, this expectation was well documented in the results shown in Figs. 5(a) and (b) where the results for the temperatures of the oil and the water are respectively shown as a function of the measurement time. Over the entire measurement time, the temperature of the substances in the cooking pot is higher in the new cooker than in the conventional cooker. This difference is particularly noted in the case of the oil over the long measurement time range. Specifically, in order to heat the oil to a temperature of $230^{\circ} \mathrm{C}$, it takes $17 \mathrm{~min}$ with the new induction cooker while it takes 3 min longer with the conventional cooker. A similar result was observed in the case of water; in order to boil the water $\left(100^{\circ} \mathrm{C}\right)$, it takes 11 min with the new induction cooker, 1 min faster than with the conventional cooker. These results are important for two reasons. First, the new device with the molded composite but without a cooling fan shows a better performance, even though the nominal power is the same. Second, the new device exhibits a higher efficiency, because more energy goes to heat up the substance in the pot, again at the same nominal power.

\section{Conclusions}

A reliable operation of an induction cooker requires that the temperature of the $\mathrm{Cu}$ wire be maintained to be as low as possible. Currently, this role is played by a cooling fan. However, the use of the cooling fan raises a reliability issue due to the attraction of dust, thereby causing a malfunction of the cooling fan. The cooling fan also increases the noise level and power consumption of the cooker. The aim of this study was to solve these problems by molding a $\mathrm{Cu}$ coil with polymer composites that have a low electrical conductivity but a high thermal conductivity. In this study, several polymer composites were fabricated and their performances were tested. It was found that an AlNbased composite showed the best performance. The composite was molded with $\mathrm{Cu}$ wire and a heat sink, and this molded structure was installed into a commercial induction cooker for characterization. The results for the temperature measured near the $\mathrm{Cu}$ coil and also at the heat sink indicated that the heat generated in the $\mathrm{Cu}$ coil is efficiently dissipated through the composite. These results suggest that the new induction cooker, with the molded composite, can be operated for an extended period of time without the use of a cooling fan. It was also found that the new device shows an enhanced efficiency compared to conventional cookers, the substance (oil or water) in the cooking pot increasing in temperature more rapidly at a given power input. This increase in the efficiency is due to the removal of the cooling fan that cools down the cooking pot (and hence the substances within it).

\section{Acknowledgments}

This research was financially supported by a grant to MEMS Research Center for National Defense funded by Defense Acquisition Program Administration.

\section{References}

[1] T. Davies and P. Simpson, Induction Heating Handbook, McGraw-Hill, London (1979).

[2] H. C. Chen and K. H. Huang, Int. J. Appl. Electromagn. Mech. 28, 413 (2008).

[3] H. H. J. M. Janssen, E. J. W. ter Maten, and D. van Houwelingen, IEEE. Trans. Magn. 30, 3331 (1994).

[4] C. Y. Hsieh and S. L. Chung, J. Appl. Poly. Sci. 102, 4734 (2006).

[5] K. C. Yung and H. Liem, J. Appl. Poly. Sci. 106, 3587 (2007).

[6] Y. Xu, D. D. L. Chung, and C. Mroz, Compos: Part A 32, 1749 (2001).

[7] E. S. Lee, S. M. Lee, W. R. Cannon, and D. J. Shanefield, Colloid. Surface. A 316, 95 (2008).

[8] Dipo Electronics, http://www.dipoelec.com.

[9] CJ Cheiljedang Corporation, http://english.cj.net.

[10] R. E. Haimbaugh, Practical Induction Heat Treating, ASM International, Ohio (2001).

[11] J. Kwon, Y. J. Nam, K. H. Shin, and S. H. Lim (unpublished results). 